\title{
The perennial search for alternatives to corticosteroids in rheumatology: is there light at the end of the tunnel?
}

\author{
Durga Prasanna Misra ${ }^{1}$ (D) Vikas Agarwal $^{1}$
}

Received: 17 August 2020 / Revised: 17 August 2020 / Accepted: 20 August 2020 / Published online: 22 August 2020

(C) International League of Associations for Rheumatology (ILAR) 2020

Rheumatology as a specialty has undergone dramatic transformation in the available armamentarium for treatment options during the past seven decades, ever since the use of corticosteroids was first described in rheumatoid arthritis (RA). However, the recent article by Wang and Panush in the journal suggests that little has changed during this time with regard to corticosteroid use [1]. Particularly concerning was the fact that nearly two-thirds of patients with systemic lupus erythematosus (SLE) admitted to their wards were on high-dose corticosteroids, similar to the proportion of patients in a historical control of lupus patients from the 1950s [1,2]. The comparisons for patients with RA were probably hindered by the smaller number of patients (nine), most of whom were on corticosteroids, when compared with nearly two-thirds in the 1980s and early 1990s and one-third in the late 1990s and 2000s $[1,3]$. However, there were issues associated with the chosen historical controls [4]. Although both lupus cohorts were hospital-based, the clinical characteristics of the lupus cohort in the 1950s as well as in the present study were not available; hence, inferences about severity of disease and the need for immunosuppressive therapy could not be made $[1,2]$. The comparisons for RA patients, based on hospitalized patients in the present study with population-based historical cohorts, were more difficult to justify $[1,3]$. Nevertheless, the authors have raised an important point about the need to evaluate critically the status of therapeutic strategies for rheumatic diseases that minimize corticosteroid use. This is particularly an ethical issue in high-income countries; costlier, newer therapies are more accessible than in lesser economically developed regions of the world. In this article, we revisit the adverse effects associated with corticosteroid therapy and

Durga Prasanna Misra

durgapmisra@gmail.com

1 Department of Clinical Immunology and Rheumatology, Sanjay Gandhi Postgraduate Institute of Medical Sciences (SGPGIMS), Lucknow, India critically evaluate how far we have actually reached in our search for lesser evils as alternatives to corticosteroids.

\section{Problems associated with corticosteroid use}

Corticosteroids are associated with a number of metabolic adverse effects. Bone loss starts to set in within weeks of corticosteroid use and is related to multiple factors, including reduction of calcium absorption, increased calciuria, and alteration of osteoblast-osteoclast balance. Other musculoskeletal adverse effects include osteonecrosis (particularly in situations associated with underlying hypercoagulable states such as lupus with antiphospholipid antibodies) and steroidinduced myopathy. Patients treated with corticosteroids are prone to develop dysglycemia and hypertension and have a greater predisposition to develop atherosclerosis. Altered fat distribution leads to moon facies, buffalo hump, and cutaneous striae. Ocular side effects include increased intraocular pressures and premature posterior subcapsular cataracts. Initial high-dose corticosteroid therapy can occasionally result in steroid psychosis [5]. There is an increased predisposition towards systemic infections, particularly in those treated with pulse bolus corticosteroids used in life-threatening organ involvement in lupus or small vessel vasculitis [6].

In a large multicentric cohort of 1722 lupus patients, most of whom were young (mean age 35 years) with a disease duration of about 1 year at enrollment, and the use of corticosteroids was associated with 1.64 times higher rate of developing damage features [7]. In another cohort of 735 patients with antineutrophil cytoplasmic antibody (ANCA)-associated vasculitis (AAV) enrolled in various clinical trials conducted by the European Vasculitis Study Group (EUVAS), a significant proportion of treatment-related damage was due to hypertension, diabetes mellitus, and osteoporosis, all of which are known adverse effects of corticosteroid use [8]. Thus, the use of corticosteroids comes at a significant cost and potentially little benefit on long-term outcomes despite apparently 
controlling disease activity, as highlighted by Wang and Panush [1].

\section{Alternatives to corticosteroids in rheumatoid arthritis}

Conventionally, patients with RA generally required on lowdose oral corticosteroids along with conventional diseasemodifying antirheumatic drugs (DMARDs), with a tapering and stopping of corticosteroid use by 6-9 months once the effect of DMARDs sets in. Over the past two decades, biological DMARDs (bDMARDs) and lately targeted synthetic DMARDs (tsDMARDs) have been increasingly used to help attain remission or low disease activity state as earlier options after initial failure of methotrexate monotherapy [9]. Overall, bDMARDs probably help achieve remission or low disease activity earlier than cDMARDs, although eventually to a similar degree in both instances [10]. Recent evidence suggests that some tsDMARDs like upadacitinib might actually be superior to bDMARDs for controlling disease activity in RA [11]. It is possible that earlier bDMARD and tsDMARD use might obviate the need for high-dose oral corticosteroids, as were previously used in the COBRA trial [12]. Earlier issues regarding the accessibility to bDMARDs in low- and middleincome countries were mostly based on significantly higher costs as well as concerns about safety [13]. Recent literature has proven to be reassuring in this regard. The availability of biosimilar drugs as more cost-effective alternatives has resulted in a wider access to bDMARDs across the world [14]. Literature regarding the persistence of biosimilars in patients switched from innovator bDMARDs to biosimilars is encouraging. A recent report suggested that nearly $85 \%$ patients were able to continue biosimilars 1 year after switching [15]. The endemicity of tuberculosis infection has been another concern in low-middle-income countries because of the increased risk of infections, particularly tuberculosis reactivation, with bDMARDs. However, recent data has been reassuring in this regard. In a cohort of 411 patients from India treated with bDMARDs for various rheumatic diseases, baseline screening identified latent tuberculosis infection (LTBI) in 8\%. None of these patients underwent tuberculosis reactivation despite bDMARD use after receiving appropriate chemoprophylaxis for tuberculosis. A further $4 \%$ patients who had a negative screen for LTBI at baseline went on to develop clinically evident tuberculosis, suggesting the need for continued vigilance during follow-up of these patients [16]. Another study of 209 patients from the same cohort developed serious infections (other than tuberculosis) in $<2 \%$ individuals [17]. Another Indian study screened 730 patients with various rheumatic diseases for LTBI using both interferon gamma release assay (IGRA) and Mantoux test (with 10 Tuberculin units) and identified LTBI in $37 \%$ individuals, who received appropriate chemoprophylaxis prior to initiating bDMARDs. This cohort of 730 patients was compared with 2930 others treated at the same center without bDMARDs. Both groups had similar proportions of patients developing clinical tuberculosis (about $0.6 \%$ ) on follow-up [18]. Thus, appropriate screening strategies for detecting LTBI before initiating bDMARDs helped minimize the risk of incident tuberculosis infection (de novo or reactivation) even in high-endemic regions for tuberculosis.

\section{Alternatives to corticosteroids in systemic lupus erythematosus}

Numerous efforts have been made to minimize corticosteroid use in lupus due to the aforementioned problems of higher rates of damage accrual in patients on glucocorticoids [7]. The RITUXILUP trial attempted a regimen for remission induction in lupus nephritis with rituximab and mycophenolate mofetil but without oral corticosteroids in 50 patients. The results were highly encouraging, with $90 \%$ patients attaining remission by a median of 37 weeks. However, a majority of the cohort comprised membranous lupus nephritis rather than proliferative lupus nephritis (which is more severe), thereby limiting the generalizability of the study findings to more severe lupus nephritis phenotypes [19]. The antagonist of B cell activation factor, belimumab, has demonstrated steroid-sparing effect across multiple lupus trials [20], hence holds promise for evaluation as an alternative to corticosteroid in lupus patients at initial presentation, at least in regions of the world where cost of therapy is not such a significant constraint. There is some evidence that therapies such as tacrolimus targeting p-glycoprotein expression on lymphocytes, which is a marker of steroid resistance, might help reduce corticosteroid dose requirement [21]. Tacrolimus is already proven to be of benefit for the induction of remission in lupus nephritis, particularly in Asian populations [22]. The role of tacrolimus as a cheap steroid-sparing agent in SLE requires wider exploration in settings where access to bDMARDs is limited.

\section{Alternatives to corticosteroids in AAV}

ANCA-associated vasculitis is probably the one disease where pauci-steroid regimens have shown the greatest promise. In a pilot study of 20 patients with AAV from North America, a regimen with intravenous rituximab and oral corticosteroids tapered and stopped over 8 weeks could help attain remission in $14 / 20$ patients. The limitation of this study was that patients with more severe AAV manifestations such as severe pulmonary hemorrhage or rapidly progressive renal failure were excluded [23]. Another study from the UK utilized a combined regimen of cyclophosphamide and rituximab for remission induction in AAV. Corticosteroids were only administered 
for 1-2 weeks in these 49 patients. Of these, $96 \%$ were in remission at 6 months and $90 \%$ at 12 months [24]. Although some questions have been raised regarding the lower disease severity in this cohort of patients [25], the findings are encouraging regarding the feasibility of reducing steroids in induction regimens of AAV. Greater understanding of the pathogenesis of AAV has revealed alternative complement factor pathway activation as a major event in neutrophil priming in AAV [26]. The complement 5a receptor inhibitor avacopan has been recently tried for remission induction in AAV. An earlier phase II trial suggested the feasibility of a regimen without corticosteroids for remission induction in AAV [27]. The preliminary results of the recently completed phase III trial of avacopan in 330 patients with AAV (166 treated with avacopan, 164 treated with corticosteroids) along with cyclophosphamide (followed by azathioprine) or rituximab identified avacopan as non-inferior to prednisone at 26 weeks for attainment of remission. At 52 weeks, avacopan was superior to prednisone, wherein $66 \%$ patients in the avacopan arm attained remission compared with 55\% in the prednisone group. Importantly, avacopan continued to have better improvement of renal function than prednisone even in those with severe renal impairment at baseline [28]. These findings hold reasonable promise for a future in the management of small vessel vasculitis management without corticosteroids even in the remission induction regimen.

\section{Future perspectives}

The authors would opine that there is considerable promise for corticosteroid-naïve or pauci-corticosteroid regimens for the management of common rheumatic diseases like RA as well as serious multisystemic rheumatic diseases like lupus and AAV. However, there remains a need to evaluate optimal regimens for such situations, which are likely to be diseasespecific. Until such regimens are widely accepted, every attempt should be made by treating rheumatologists to minimize corticosteroid dose and duration, as well as institute appropriate protective strategies for bone health while monitoring for metabolic complications, vascular health, and other adverse effects of corticosteroids.

Authors' contributions DPM and VA both contributed to the conception and design of the work, acquisition, analysis, and interpretation of data for the work. DPM drafted the work, and VA revised it critically for important intellectual content. Both DPM and VA provide final approval of the version to be published and agree to be accountable for all aspects of the work in ensuring that questions related to the accuracy or integrity of any part of the work are appropriately investigated and resolved.

\section{Compliance with ethical standards}

Disclosures None.
Ethical approval This article does not contain any studies with human participants or animals performed by any of the authors.

\section{References}

1. Wang S, Panush R (2020) Certain perspectives about the use of corticosteroids for managing hospitalized patients with rheumatic diseases. Clin Rheumatol

2. Albert DA, Hadler NM, Ropes MW (1979) Does corticosteroid therapy affect the survival of patients with systemic lupus erythematosus? Arthritis Rheum 22:945-953. https://doi.org/10.1002/art. 1780220901

3. Makol A, Davis JM 3rd, Crowson CS, Therneau TM, Gabriel SE, Matteson EL (2014) Time trends in glucocorticoid use in rheumatoid arthritis: results from a population-based inception cohort, 1980-1994 versus 1995-2007. Arthritis Care Res (Hoboken) 66: 1482-1488. https://doi.org/10.1002/acr.22365

4. van Rosmalen J, Dejardin D, van Norden Y, Löwenberg B, Lesaffre E (2018) Including historical data in the analysis of clinical trials: is it worth the effort? Stat Methods Med Res 27:3167-3182. https://doi.org/10.1177/0962280217694506

5. Dua A, Das P, Ravindran V (2019) Glucocorticoids: a review of its adverse effects including bone loss. Indian J Rheumatol 14:90-98. https://doi.org/10.4103/0973-3698.272158

6. Youssef J, Novosad SA, Winthrop KL (2016) Infection risk and safety of corticosteroid use. Rheum Dis Clin N Am 42:157-x. https://doi.org/10.1016/j.rdc.2015.08.004

7. Bruce IN, Keeffe AG, Farewell V et al (2015) Factors associated with damage accrual in patients with systemic lupus erythematosus: results from the systemic lupus international collaborating clinics (SLICC) inception cohort. Ann Rheum Dis 74:1706-1713. https:// doi.org/10.1136/annrheumdis-2013-205171

8. Robson J, Doll H, Suppiah R, Flossmann O, Harper L, Höglund P, Jayne D, Mahr A, Westman K, Luqmani R (2015) Damage in the anca-associated vasculitides: long-term data from the European vasculitis study group (EUVAS) therapeutic trials. Ann Rheum Dis 74:177-184. https://doi.org/10.1136/annrheumdis-2013203927

9. Smolen JS, Landewé RBM, Bijlsma JWJ, Burmester GR, Dougados M, Kerschbaumer A, McInnes IB, Sepriano A, van Vollenhoven RF, de Wit M, Aletaha D, Aringer M, Askling J, Balsa A, Boers M, den Broeder AA, Buch MH, Buttgereit F, Caporali R, Cardiel MH, de Cock D, Codreanu C, Cutolo M, Edwards CJ, van Eijk-Hustings Y, Emery P, Finckh A, Gossec L, Gottenberg JE, Hetland ML, Huizinga TWJ, Koloumas M, Li Z, Mariette X, Müller-Ladner U, Mysler EF, da Silva JAP, Poór G, Pope JE, Rubbert-Roth A, Ruyssen-Witrand A, Saag KG, Strangfeld A, Takeuchi T, Voshaar M, Westhovens R, van der Heijde D (2020) EULAR recommendations for the management of rheumatoid arthritis with synthetic and biological diseasemodifying antirheumatic drugs: 2019 update. Ann Rheum Dis 79: 685. https://doi.org/10.1136/annrheumdis-2019-216655

10. Parida JR, Misra DP, Wakhlu A, Agarwal V (2015) Is nonbiological treatment of rheumatoid arthritis as good as biologics? World J Orthop 6:278-283. https://doi.org/10.5312/wjo.v6.i2.278

11. Fleischmann RM, Genovese MC, Enejosa JV, Mysler E, Bessette L, Peterfy C, Durez P, Ostor A, Li Y, Song IH (2019) Safety and effectiveness of upadacitinib or adalimumab plus methotrexate in patients with rheumatoid arthritis over 48 weeks with switch to alternate therapy in patients with insufficient response. Ann Rheum Dis 78:1454-1462. https://doi.org/10.1136/annrheumdis2019-215764

12. Boers M, Verhoeven AC, Markusse HM, van de Laar MAFJ, Westhovens R, van Denderen JC, van Zeben D, Dijkmans BAC, 
Peeters AJ, Jacobs P, van den Brink HR, Schouten HJA, van der Heijde DMFM, Boonen A, van der Linden S (1997) Randomised comparison of combined step-down prednisolone, methotrexate and sulphasalazine with sulphasalazine alone in early rheumatoid arthritis. Lancet 350:309-318. https://doi.org/10.1016/s01406736(97)01300-7

13. Misra DP, Sharma A, Agarwal V (2018) Rheumatology science and practice in India. Rheumatol Int 38:1587-1600. https://doi. org/10.1007/s00296-018-4111-4

14. Rath PD, Chen DY, Gu J, Lee VWY, al Ani NA, Shirazy K, Llamado L (2019) Anti-tumor necrosis factor biosimilars and intended copies in rheumatology: perspective from the Asia Pacific region. Int J Rheum Dis 22:9-24. https://doi.org/10.1111/ 1756-185x.13371

15. Provenzano G, Arcuri C, Miceli MC (2020) Open-label non-mandatory transitioning from originators to biosimilars in routine clinical care. Clin Rheumatol. https://doi.org/10.1007/s10067-02005327-6

16. Shobha V, Rao V, Desai A, Jois R, Srikantiah C, Dharmanand BG, Kumar S, Kumar P, Dharmapalaiah C, Mahendranath KM, Prasad S, Daware M, Singh Y, Karjigi U (2019) Prescribing patterns and safety of biologics in immune-mediated rheumatic diseases: Karnataka biologics cohort study group experience. Indian $\mathrm{J}$ Rheumatol 14:17-20. https://doi.org/10.4103/injr.injr_79_18

17. Chandrashekara S, Shobha V, Rao V, Desai A, Jois R, Dharmanand BG, Kumar S, Kumar P, Dharmapalaiah C, Mahendranath KM, Prasad S, Daware MA, Singh Y, Karjigi U, Nagaraj S, Anupama KR (2019) Incidence of infection other than tuberculosis in patients with autoimmune rheumatic diseases treated with bDMARDs: a real-time clinical experience from India. Rheumatol Int 39:497507. https://doi.org/10.1007/s00296-019-04245-4

18. Malaviya A, Thakaran R, Rawat R, Kapoor S, Garg S, Baghel SS, Messi C, Vivekanand, Zaheer Q (2018) Real life experience of a screening strategy for latent tuberculosis before treatment with biologicals in indian patients with rheumatic diseases. Indian $\mathrm{J}$ Rheumatol 13:233-239. https://doi.org/10.4103/injr.injr 6618

19. Condon MB, Ashby D, Pepper RJ, Cook HT, Levy JB, Griffith M, Cairns TD, Lightstone L (2013) Prospective observational singlecentre cohort study to evaluate the effectiveness of treating lupus nephritis with rituximab and mycophenolate mofetil but no oral steroids. Ann Rheum Dis 72:1280-1286. https://doi.org/10.1136/ annrheumdis-2012-202844
20. Oon S, Huq M, Godfrey T, Nikpour M (2018) Systematic review, and meta-analysis of steroid-sparing effect, of biologic agents in randomized, placebo-controlled phase 3 trials for systemic lupus erythematosus. Semin Arthritis Rheum 48:221-239. https://doi. org/10.1016/j.semarthrit.2018.01.001

21. Chowdhary V (2020) When doing the right thing is wrong - drug efflux pumps in steroid-resistant nephrotic syndrome. Indian J Rheumatol 15:1-2. https://doi.org/10.4103/0973-3698.281583

22. Hannah J, Casian A, D'Cruz D (2016) Tacrolimus use in lupus nephritis: a systematic review and meta-analysis. Autoimmun Rev 15:93-101. https://doi.org/10.1016/j.autrev.2015.09.006

23. Miloslavsky EM, Niles JL, Wallace ZS, Cortazar FB, Fernandes A, Laliberte K, Stone JH (2018) Reducing glucocorticoid duration in ANCA-associated vasculitis: a pilot trial. Semin Arthritis Rheum 48:288-292. https://doi.org/10.1016/j.semarthrit.2018.01.013

24. Pepper RJ, McAdoo SP, Moran SM et al (2019) A novel glucocorticoid-free maintenance regimen for anti-neutrophil cytoplasm antibody-associated vasculitis. Rheumatology (Oxford) 58: 260-268. https://doi.org/10.1093/rheumatology/key288

25. Patro P, Agarwal V, Misra DP (2019) Comment on: a novel glucocorticoid-free maintenance regimen for anti-neutrophil cytoplasm antibody-associated vasculitis. Rheumatology (Oxford) 58: 1117-1119. https://doi.org/10.1093/rheumatology/kez036

26. Nakazawa D, Masuda S, Tomaru U, Ishizu A (2019) Pathogenesis and therapeutic interventions for ANCA-associated vasculitis. Nat Rev Rheumatol 15:91-101. https://doi.org/10.1038/s41584-0180145-y

27. Jayne DRW, Bruchfeld AN, Harper L, Schaier M, Venning MC, Hamilton P, Burst V, Grundmann F, Jadoul M, Szombati I, Tesař V, Segelmark M, Potarca A, Schall TJ, Bekker P, CLEAR Study Group (2017) Randomized trial of C5a receptor inhibitor avacopan in ANCA-associated Vasculitis. J Am Soc Nephrol 28:2756-2767. https://doi.org/10.1681/asn.2016111179

28. Jayne D, Merkel P, Yue H, Schall TJ, Kelleher C, Bekker P (2020) LB003A randomized, double-blind, active controlled study of avacopan in anti-neutrophil cytoplasmic antibody-associated vasculitis [abstract]. Nephrol Dial Transplant 35. https://doi.org/10.1093/ ndt/gfaa146.LB003

Publisher's note Springer Nature remains neutral with regard to jurisdictional claims in published maps and institutional affiliations. 